\title{
Infection Control Practices in Endoscopy Room in COVID-19 Era
}

\author{
Piramanayagam Paramasivan ${ }^{1}$ \\ ${ }^{1}$ Department of Medical Gastroenterology, Apollo Hospitals,
Chennai, Tamil Nadu, India
}

J Digest Endosc 2020;11:67-68

COVID-19, the highly contagious disease caused by the novel SARS-CoV-2 virus, has been declared as pandemic by the World Health Organization. Till the time an effective antiviral treatment or vaccine becomes available, adopting best infection control practices appear to be the cornerstone of managing this pandemic. Infection control practice in the endoscopy room should address three important aspectspersonnel, equipment, and environment.

\section{Personnel: Patients and Health Care Personnel}

Guidelines from endoscopy societies have outlined appropriate selection for patients for endoscopy during the pandemic phase. Patients scheduled for endoscopy should be educated about social distancing, cough etiquette, and wearing of mask. Proper hand hygiene and appropriate use of personal protective equipment for health care workers are recommended to decrease the risk of transmission of SARS-CoV-2.

\section{Equipment: Endoscope and Accessories}

Dr. Rai, in his review, has described in detail, the standard disinfection procedures for endoscopes, which is considered effective for preventing transmission of SARS-CoV-2. ${ }^{1}$ Disposable accessories should not be reused. It is reassuring that no reports of endoscopy-related transmission of COVID-19 has been documented till now.

\section{Environment: Endoscopy Room and Patient Care Equipment in the Room}

As viral ribonucleic acid (RNA) has been detected in air samples from intensive care unit, concerns regarding aerosol transmission of SARS-CoV-2 have been raised. ${ }^{2}$ Thus, endoscopy rooms where aerosol-generating procedures are done are potentially high-risk areas for nosocomial transmission.

As reviewed by Dr. Rai, the American Gastroenterological Association and Asia Pacific Society of Digestive
Address for correspondence Piramanayagam Paramasivan, DM, 18/5, Srividhya Nagar, MMTC Colony, Nanganallur, Chennai 600061, Tamil Nadu, India (e-mail: piraman2000@yahoo.co.in).

Endoscopy (APSDE) societies recommend the use of negative pressure rooms, when available, for endoscopic procedures in patients with presumptive or proven COVID-19.,4

What are the specifications of a negative pressure room? As per the Centers for Disease Control and Prevention, airborne infection isolation rooms or negative pressure rooms are defined as single-patient rooms at negative pressure relative to the surrounding areas with following specifications:

- $\geq 12$ air changes/hour (ACH).

- Air supply and exhaust rate sufficient to maintain a $2.5 \mathrm{~Pa}$ (0.01-inch water gauge) negative pressure difference with respect to all surrounding spaces with an exhaust rate of $\geq 50 \mathrm{ft}^{3} / \mathrm{min}$.

- Air exhausted directly outside away from air intakes and traffic or exhausted after high-efficiency particulate air (HEPA) filtration prior to recirculation.

- If an anteroom is not available, use portable, industrial-grade HEPA filters in the procedure room to provide additional $\mathrm{ACH}$ equivalents for removing airborne particulates.

- Room doors should be kept closed except when entering or leaving the room, and entry and exit should be minimized. ${ }^{5}$

As most endoscopy units may not have a negative pressure room, the APSDE recommends that the procedure can be performed in a venue outside the endoscopy center, with negative pressure in the operation theater, for example, or in a room with better ventilation. ${ }^{4}$

\section{Interval between Procedures-Impact on Scheduling Procedures}

It is important to reemphasize the recommendation mentioned in review by Dr. Rai, that negative pressure rooms be kept empty for 30 minutes, and in the absence of negative pressure rooms, diluting the air with cleaner air from outdoors and leaving the room empty for 1 hour. ${ }^{6}$ This has to be borne in mind while scheduling procedures. 


\section{Disinfection of Surfaces and Patient Care Equipment in Endoscopy Room}

SARS-CoV-2 has been shown to survive on surfaces for hours to days. ${ }^{7}$ All noncritical environmental surfaces, endoscopy furniture, and floor should be considered heavily contaminated in patients with intermediate or high risk of COVID-19 and should be disinfected at the end of each procedure. ${ }^{6}$ Visibly soiled surfaces should be cleaned with detergent and, subsequently, disinfected with $1 \%$ sodium hypochlorite solution. ${ }^{8}$

The following recommendation, adapted from standard operating procedure for transporting suspected/proven COVID-19 patient issued by the Family Welfare Directorate General of Health Services, gives practical suggestions that can be implemented in the endoscopy room:

- Disinfect (damp wipe) all horizontal, vertical, and contact surfaces with a cotton cloth saturated (or microfiber) with a $1 \%$ sodium hypochlorite solution. These surfaces include, but are not limited to, stretchers, bed rails, infusion pumps, intravenous poles, monitor cables, telephone, countertops, sharps container, stethoscopes, blood pressure cuffs, monitors, backboards, and immobilization devices, laryngoscope blades, shelves, and door handles.

- Spot clean walls (when visually soiled) with disinfectant detergent and windows with glass cleaner. Allow contact time of 30 minutes and allow the air to dry. Damp mop floor with $1 \%$ sodium hypochlorite disinfectant.

- Discard disposable items and infectious waste in a biohazard bag. The interior is sprayed with $1 \%$ sodium hypochlorite. The bag is tied and the exterior is also decontaminated with $1 \%$ sodium hypochlorite and should be disposed according to hospital policy. ${ }^{9}$

Although viral RNA and live virus have been cultured from stool samples of COVID-19 patients, there is no evidence to date that transmission through sewage has occurred. Available information suggests that standard municipal wastewater system chlorination practices are said to be sufficient to inactivate coronaviruses. ${ }^{8}$

\section{Conclusion}

COVID-19 pandemic has brought to the fore the need for strict adoption of infection control practices in endoscopy room to prevent nosocomial transmission. Constructing negative pressure rooms and meticulous disinfection of surfaces after each procedure and the need to schedule procedures with adequate interval between them are likely to alter the way we work in the near future.

\section{Conflict of Interest}

None declared.

\section{References}

1 Praveer Rai. Disinfection of Endoscopy and Reusability of Accessories. J Digest Endosc 2020;11:61-66

2 Guo Z-D, Wang Z-Y, Zhang S-F, et al. Aerosol and surface distribution of severe acute respiratory syndrome coronavirus 2 in hospital wards, Wuhan, China. Emerg Infect Dis 2020;26(7):10.3201/eid2607.200885

3 Sultan S, Lim JK, Altayar O, et al; AGA. AGA institute rapid recommendations for gastrointestinal procedures during the COVID-19 pandemic. Gastroenterology 2020;S00165085(20)30458-310.1053/j.gastro.2020.03.072

4 Chiu PWY, Ng SC, Inoue H, et al. Practice of endoscopy during COVID-19 pandemic: position statements of the Asian Pacific Society for Digestive Endoscopy (APSDE-COVID statements). Gut 2020;:gutjnl-2020-32118510.1136/gutjnl-2020-321185

5 Centre for Disease Control and Prevention-Interim Infection Prevention and Control Recommendations for Patients with Suspected or Confirmed Coronavirus Disease. 2019 (COVID-19) in Healthcare Settings (Updated April 13, 2020). Available at: https://www.cdc.gov/coronavirus/2019-ncov/ hcp/infection-control-recommendations.html. Accessed April 27, 2020

6 Repici A, Maselli R, Colombo M, et al. Coronavirus (COVID-19) outbreak: what the department of endoscopy should know. Gastrointest Endosc 2020;:S0016-5107(20)30245-510.1016/j. gie.2020.03.019

7 van Doremalen N, Bushmaker T, Morris DH, et al. Aerosol and surface stability of SARS -CoV-2 as compared with SARSCoV-1. N Engl J Med 2020;382(16):1564-1567

8 Center for Disease Control and Prevention. Guideline for disinfection and sterilisation in healthcare facilities 2008; Cleaning and disinfecting environmental surfaces in healthcare facilities. Available at: https://www.cdc.gov/ infection control/ guidelines/disinfection/healthcare-equipment.html. Accessed April 20, 2020

9 Ministry of Health and Family Welfare. Directorate General of Health services Corona Virus Disease 2019. "Standard Operating Procedure (SOP) for transporting a suspect/ confirmed case of COVID-19. Available at: https://www. mohfw.gov.in/pdf/StandardOperatingProcedureSOPfortransportingasuspectorconfirmedcaseofCOVID19.pdf. Accessed April 27, 2020. 